\title{
Constructing a Three-Part Instrument for Emotional Intelligence, Social Intelligence and Learning Behavior
}

\author{
Mali Praditsang \\ School of Education \& Modern Language, College of Art \& Sciences, Universiti Utara Malaysia, Kedah, Malaysia \\ Email:noomom@hotmail.com
}

Zahyah Hanafi, Ph.D

School of Education \& Modern Languages, College of Arts \& Sciences, Universiti Utara Malaysia, Kedah, Malaysia Email: zahyah@uum.edu.my

\section{Doi:10.5901/mjss.2015.v6n2p489}

\section{Abstract}

This study aims to construct an instrument to measure emotional intelligence and social intelligence and how they can influence students' learning behavior. A dearth of local instruments in this field has notably been recorded low or insufficient. The study thus recognizes the importance of commoditizing a functional tool which will contribute to furthering local studies along this area. The content validity of the questionnaire was verified using Index Objective Congruence (IOC) by five experts: one Malaysian and four Thai selected based on their academic positions and teaching experience. The questionnaire was revised after their feedback and the total items now comprised 40 items on emotional intelligence, 51 on social intelligence and 51on learning behavior. It was piloted with forty-two first year students from a university in southern Thailand and the Cronbach's Alpha value was 0.726 for emotional intelligence, 0.828 for social intelligence and 0.892 for learning behavior which suggested the high level of strength of the items in all the variables.

Keywords: Emotional Intelligence, Social Intelligence, Learning Behavior, University Students.

\section{Introduction and Overview}

This study focused on constructing an instrument to study the level of emotional intelligence, social intelligence and learning behavior and the relationship between these variables. The relationship among the variables was constructed based on Goleman's $(1998,2006)$ theory on emotional intelligence and social intelligence and Claire Weinstein and David Palmer's (2002) Learning and Study Strategies Inventory (LASSI).

According to Goleman (1998), emotional intelligence is the ability to be patient and wait for a commitment to be consciously accomplished. It involves understanding how individuals handle conflicts with their own emotions and how they built a good relationship with people around them. Hence, emotional intelligence in this study would refer to two subdimensions; personal competence and social competence.

The first sub-dimension, personal competence is further divided into three sub-dimensions; self-awareness, selfregulation and motivation. The first sub-dimension, self-awareness determines how one recognizes his/her emotions and its effects. Self-awareness is further divided into three areas: emotional awareness (recognizing one's emotions and its effects), accurate self-assessment (knowing what one's strengths and limits are), self-confidence (having a strong sense of one's own value and capabilities). Next is self-regulation (management of one's internal states, impulses and resources). Self-regulation can further be divided into five areas: self-control (monitoring disruptive emotions and impulses), trustworthiness (sustaining honesty and integrity standard), consciousness (being responsible for one's own performance), adaptability (being flexible in coming to terms with changes) and innovation (feeling easy with new ideas, approaches and information). The third sub-dimension is motivation (tendencies influenced by emotion that navigate or facilitate goal achievement). This can further be divided into four areas: achievement driven or perseverance in an attempt to reach goals, commitment or keeping with group or organization goals, initiative or the readiness to act as opportunities come and optimism or unfailing attempts to pursue goals in spite of obstacles.

The second sub-dimension of Emotional Intelligence is social competence which is concerned with how one deal with relationships. This can further be divided into two areas; empathy and social skills. Empathy is the perceptiveness of 
feelings, needs and concerns of others and can be further divided into 1) understanding others - awareness of others' feeling and being in earnest about what they strongly feel, 2) developing others - knowing what others' needs are and support their abilities, 3) service orientation - foreseeing, recognizing and serving customers' needs, 4) leveraging diversity - opening opportunities via different types of people and 5) political awareness - understanding what a group currently feels and hierarchical relationships. Social skills can be further be divided into eight areas: 1) influence - using effective tactics to persuade, 2) communication - listening and responding, 3) conflict management - managing disagreements by negotiation, 4) leadership - inspiring and guiding others either individual or group, 5) change catalyst instilling/managing change, 6) building bonds - fostering instrumental relationships, 7) collaboration and cooperation joint working with others for goals which are shared, and 8) team capabilities - putting drive into group's pursuit of shared goals (Goleman, 1998).

Social intelligence in this study refers to the students' ability to live with others in a society. A socially intelligent student understands the needs of the society. He/she can adapt his/her behavior or demeanor in accordance with the conditions of social efficiency. The student knows how to build good relationships with others in the society and can live happily within the society. Social intelligence is further divided into two sub-dimensions; social awareness and social facility (Goleman, 2006; Thongsuebsai, 2009). Social awareness includes primal empathy, attunement, empathic accuracy and social cognition. Briefly, primal empathy describes one's ability to sense nonverbal signals and to feel with others. Attunement relates to listening and attuning completely with others. Empathic accuracy concerns understanding of other's feelings, intentions and thoughts. Social cognition concerns what one knows about the mechanism of the social world.

The second sub-dimension of social intelligence is social facility which can further be divided into synchrony, selfpresentation, and influence and concern. Social facility is what is naturally carried on from social awareness. It allows for one's sense and knowledge of another to be used to develop smooth and effective interactions. Synchrony concerns the smooth interactions on a nonverbal level. Self-presentation refers to the effective presentation of self. Influence involves the ability to shape the outcome of social interactions. Concern is related to recognizing the needs of others, caring about these needs and taking appropriate actions to affect this care. Goleman explained that the high road abilities concerning social cognition and the low road functions concerning nonverbal abilities are mixed together in this model of social intelligence (Goleman, 2006).

Issues on learning behavior, on the other hand, were examined based on Claire Weinstein and David Palmer's (2002) Learning and Study Strategies Inventory (LASSI). In this study, learning behavior is defined by how a student learns overtly (openly) and covertly (within one's mind which cannot be observed by others). There are three factors involved in determining one's covert learning behavior: attitude, motivation and anxiety. 1) Attitude refers to the measures on self-motivation and desire to succeed. A low score indicates the student needs to learn how to set goals. 2) Motivation on the other hand, refers to measures on how well students apply themselves to their study and their willingness to succeed. A low score indicates the need to learn how to set goals and 3) Anxiety refers to the measures on the level of worry a student has regarding his/her study. A low score indicates the student needs to learn coping techniques. Overt behavior comprised seven factors: 1) Time management refers to the ability of a student to create a schedule and manage his/her workload. A low score indicates the student need to learn how to create a timetable and deal with distractions and other goals. 2) Concentration is the student's ability to focus on academic tasks. A low score indicates that the student should learn techniques to focus attention and maintain concentration. 3) Information processing is the ability of a student to activate his/her prior knowledge of a topic in order to make connections between old and new information and then to organize the new information meaningfully. A low score indicates that the student should focus on learning ways of organizing what he/she is learning. 4) Selecting main idea refers to the student's ability to discern important information requiring further attention. A low score indicates the student needs to learn ways of identifying main ideas from supporting ones. 5) Study aids is the student's ability to access and use both materials (headings, subheading within a text) and supporting structures (study group). A low score indicates the student needs to learn what is available and how resources can be used. 6) Self-testing measures the students' ability to review materials and assess what has been understood from learning and what needs further attention. A low score indicates that the student should learn strategies to review and monitor his/her understanding of the materials. 7) Test strategies measure the student's ability to prepare for and take examination. A low score indicates the student needs to learn test preparation strategies as well as test taking strategies.

\section{Methodology}

The procedure in constructing the questionnaire is as follows. 


\section{The Construction of the Items}

The questionnaire item construction was done by using the information from the literature review, including Goleman's (1998; 2006) theories on Emotional Intelligence and Social Intelligence and Weinstein and Palmer's (2002) Learning and Study Strategies Inventory (LASSI).

\section{Questionnaire Construction Procedure}

The instrument used in collecting the data is a questionnaire which was designed by the researchers based on related ideology, theories and literature as well as existing instrument. It is composed of 3 parts:

Part 1: Emotional Intelligence items: This covers 5 sub-dimensions: 1) self-awareness, 2) self-regulation, 3) motivation, 4) empathy and 5) social skills. Emotional Intelligence Instrument was developed from Daniel Goleman's Emotional Intelligence Theory (1998) and Phatthanaphong's research (2007). Goleman's theory on Emotional Intelligence identifies the Emotional Intelligence components (Goleman, 1998) which were studied to develop the objectives of the Emotional Intelligence instrument and to make certain that essential items in it were embraced in the Emotional Intelligence theory framework. It consists of 5 sub-dimensions:

Table 1: The content to be measured covers all the emotional intelligence variables in the study and serves the study objectives

\begin{tabular}{|l|l|l|}
\hline \hline 1 & Self-awareness & $\begin{array}{l}\text { Ability to recognize his/her own feelings and emotions, know the cause of these emotions, express his/her own } \\
\text { feelings, assess his/her situation, know about his/her strengths and weaknesses, have self-confidence in his/her } \\
\text { own abilities and evaluate himself/herself. }\end{array}$ \\
\hline 2 & Self-regulation & $\begin{array}{l}\text { Ability to manage his/her own emotions, control inner feelings, deal with his/her own state of mind, adapt to } \\
\text { changes and have an open mind towards new situations, knowledge and happiness. }\end{array}$ \\
\hline 3 & Motivation & $\begin{array}{l}\text { Ability to drive forward and strive to achieve a goal. Emotional support from parents and peers assists his/her } \\
\text { ability to do better and achieve his/her goals and overcome barriers he/she may encounter. }\end{array}$ \\
\hline 4 & Empathy & $\begin{array}{l}\text { Ability in recognizing the needs and feelings of others, being interested in the feelings of others and responding to } \\
\text { the needs of others. }\end{array}$ \\
\hline 5 & Social skills & $\begin{array}{l}\text { Ability to build relationships with others so as to achieve change in a good way, to persuade people to agree to } \\
\text { what is beneficial to the public, to agree to work with others and make people around happy. }\end{array}$ \\
\hline \hline
\end{tabular}

Part 2: Social Intelligence Instrument has 2 sub-dimensions: social awareness and social facility (Goleman, 2006; Thongsuebsai, 2009). This is the instrument to assess social intelligence developed by the researchers from Goleman's theory (2006) of social intelligence and a study by Thongsuebsai (2009). The procedures in constructing and validating the scale are as follows:

Goleman's Social Intelligence Theory, especially his ideology in identifying the sub-dimensions of Social Intelligence was used in specifying the objectives of this Social Intelligence instrument. The instrument consists of 2 subdimensions: social awareness and social facility.

Table 2: The two sub-dimensions of social intelligence, namely: social awareness and social facility along with their corresponding variables are presented in the succeeding discussion.

\begin{tabular}{|c|c|l||}
\hline \multicolumn{3}{|c|}{ Social Awareness } \\
\hline \hline 1 & Primal empathy & The recognition of the emotions and feelings of others in the society as perceived by instinct. \\
\hline 2 & Attunement & $\begin{array}{l}\text { Involves an individual listening carefully to what others have to say as well as bonding with others in such a way as to } \\
\text { understand others' emotions, feelings and needs. }\end{array}$ \\
\hline 3 & Emphatic Accuracy & Refers to accurately understanding the thinking, emotions, needs and feelings of other people. \\
\hline 4 & Social cognition & $\begin{array}{l}\text { Refers to the ability of him/her to know about the society around. Social cognition will have an effect on his/her behavior } \\
\text { towards the society and this will lead him/her to adapt well to the norm of the society. }\end{array}$ \\
\hline \hline & \multicolumn{3}{|c|}{ Social Facility } \\
\hline 2 & Synchrony & $\begin{array}{l}\text { The ability to capture and understand by observing the moods of another person as expressed by that person. An } \\
\text { individual is able to understand the other person's behavior and know how the other person feels from the behavior he/she } \\
\text { display. }\end{array}$ \\
\hline 3 & Influence & $\begin{array}{l}\text { The ability of an individual through emotional expression expresses his/her feelings and let others know how he/she feels. } \\
\text { In particular, the emotional control to fit each situation. } \\
\text { The ability to direct the behavior of others toward a certain perception of a situation at that particular time. An individual } \\
\text { can attract the people around to follow the behavior he/she wants. }\end{array}$ \\
\hline 4 & Concern & The ability to respect others or think of others and to know how to help others when they are faced with problems. \\
\hline
\end{tabular}


Part 3: Learning Behavior instrument covers 2 sub-dimensions 1) covert behavior and 2) overt behavior (Weinstein \& Palmer, 2002; Sirisamphan \& Mahakhan, 2011). The Learning Behavior instrument was developed based on the Weinstein and Palmer's ideology (Weinstein \& Palmer, 2002) and the work of Sirisamphan and Mahakhan (2011). The procedure in designing and assessing its quality is as follows:

Weinstein and Palmer's (2002) Learning and Study Strategies Inventory (LASSI) was used to develop the objectives of the Learning Behavior instrument and contains the items within the frame of thought. The instrument consists of 2 components: Covert Behavior and Overt Behavior.

Table 3: The content to be measured in the table below covers all the learning behavior variables in the study and serves as the study objectives

\begin{tabular}{|c|c|l||}
\hline \multicolumn{2}{|c|}{ Covert Behavior } \\
\hline \hline 1 & Attitude & $\begin{array}{l}\text { Refers to the measures on self-motivation and the desire to succeed. A low score indicates the student needs to } \\
\text { learn how to set goals. }\end{array}$ \\
\hline 2 & Motivation & $\begin{array}{l}\text { Measures on how well a student apply himself/herself to study and his/her willingness to succeed. A low score } \\
\text { indicates the need to learn how to set goals. }\end{array}$ \\
\hline \hline 3 & Anxiety & $\begin{array}{l}\text { Refers to the measures on the level of worry a student has regarding his/her study. A low score indicates the } \\
\text { student needs to learn coping techniques. }\end{array}$ \\
\hline \hline & \multicolumn{3}{|c|}{ Overt Behavior } \\
\hline 5 & Concentration & $\begin{array}{l}\text { Refers to the ability of a student to create a schedule and manage his/her workload. A low score indicates the } \\
\text { need to learn how to create a timetable and deal with distractions and other goals. } \\
\text { how to focus to attention and maintain concentration. }\end{array}$ \\
\hline
\end{tabular}

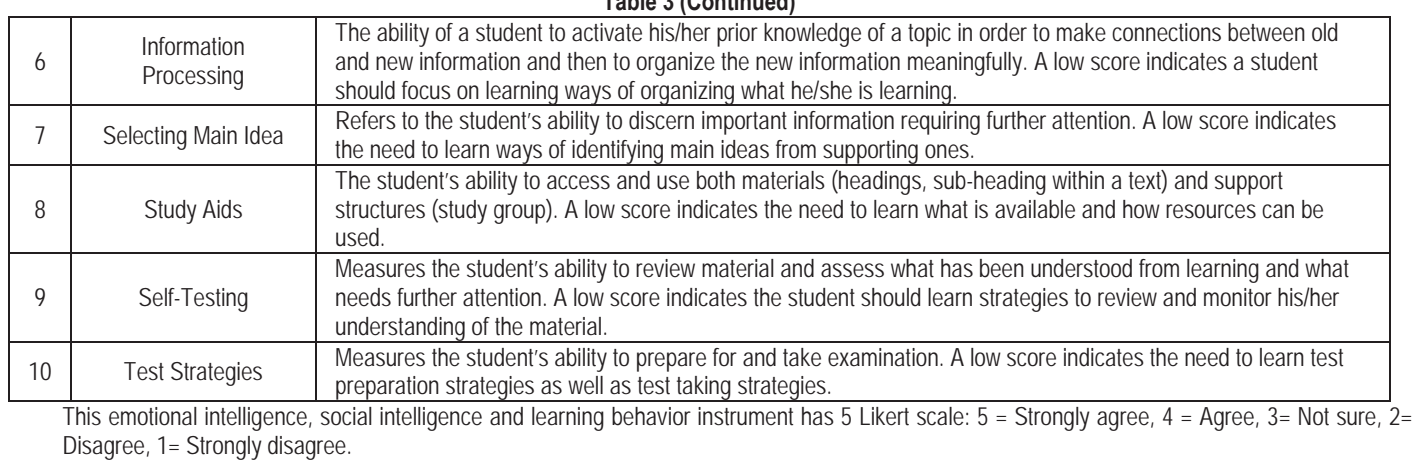

Content Verification: One expert from Malaysia and four from Thailand were selected based on their academic position, teaching experience at the university, and field of study to verify the questionnaire items using the Index of Item Objective Congruence (IOC). All the variables used were tested by previous studies for content validity and reliability. However, in this study it was tested by the Index of Item Objective Congruence (IOC) for content validity and Cronbach's Coefficient Alpha value for reliability. The reliability for emotional intelligence was 0.726 , social intelligence was 0.828 and learning behavior was 0.892 .

The revised questionnaire: The questionnaire was revised to comply with the experts' suggestions.

\section{Pilot Study}

The revised questionnaire was administered to 42 first year students at a university in southern Thailand with their background similar to the subjects in the final study. The reliability of the questionnaire items were then analyzed using Cronbach's Alpha.

\section{Results}

The First draft questionnaire consisted of 3 parts:

1) Emotional Intelligence instrument. The instrument has 48 items which covered 2 sub-dimensions (personal competence and social competence) and 5 areas: (self-awareness, self-regulation, motivation, empathy and 
social skills).

2) Social Intelligence instrument: This comprised 2 sub-dimensions (social awareness and social facility) and 8 areas (primal empathy, attunement, emphatic accuracy, social cognition, synchrony, self-presentation, influence and concern). There were 64 items in this section.

3) Learning Behavior instrument. It covers 2 sub-dimensions (covert behavior and overt behavior) and 3 areas on Covert behavior (attitude, motivation, anxiety) and 7 areas in Overt behavior (time management, concentration, information processing, selecting main idea, study aids, self-testing and test strategies). There were 75 items in this section.

Scales: There were 2 types of items in the questionnaire: positive and negative items. Five point Likert rating scale was used for the interpretation of all data on emotional intelligence, social intelligence and learning behavior.

Table 4: Positive and negative items

\begin{tabular}{|lll|lll|}
\hline \multicolumn{2}{|c|}{ Positive question } & \multicolumn{3}{c|}{ Negative question } \\
\hline \hline Strongly agree $=$ & \multicolumn{2}{c|}{} & Strongly agree & $=$ & 1 \\
\hline Agree & $=$ & 4 & Agree & $=$ & 2 \\
\hline Not sure & $=$ & 3 & Not sure & $=$ & 3 \\
\hline Disagree & $=$ & 2 & Disagree & $=$ & 4 \\
\hline Strongly disagree & $=$ & 1 & Strongly disagree & $=$ \\
\hline
\end{tabular}

Final version of the questionnaire:

Part 1: Emotional Intelligence with 40 items

Part 2: Social Intelligence with 51 items

Part 3: Learning Behavior with 51 items

A total of 142 items were in the final version of the questionnaire.

Reliability of the final draft of the questionnaire: The pilot study was done by distributing the questionnaire to 42 first year students at a university in southern Thailand, who had similar characteristics to the population in the study. The reliability of the instrument was then conducted and the result revealed the Cronbach's Alpha was 0.726 for emotional intelligence, 0.828 for social intelligence and 0.892 for learning behavior. The results showed that the item for each of the variables in the study was of high quality.

\section{Conclusion and Recommendation}

In view of the above findings, the locally-designed instrument remains as a potential tool in gauging the emotional intelligence, social intelligence, and learning behavior of students and similarly a functional tool for local users to explore for adaption and adoption. It is however recommended that standardization of the tool for its comprehensive use is forwarded for consideration.

\section{References}

Goleman, D. (1998). Working with emotional intelligence. New York, NY: Bantam.

Tongsuebsai, K. (2009). Development of a social intelligence scale for undergraduate students. Unpublished Masters thesis, Chulalongkorn University, Bangkok, Thailand.

Phatthanaphong, N. (2007). Development of a test of emotional intelligence for students in the southern Thailand school. Unpublished Master thesis, Thaksin University, Songkhla, Thailand.

Sirisamphan, O., \& Mahakhan, T. (2011). A Study of Learning Behavior of Students in Faculty of Education, Silpakorn University. Veridian E-Journal, Silpakorn University, 4, September- December 2011. Retrieved from: http://www.ejournal.su.ac.th/upload/ 198.pdf.

Weinstein, C. E., \& Palmer, D. R. (2002). LASSI user's manual for those administering the Learning and Study Strategies Inventory, Second Edition. Clearwater, FL: H \& H Publishing Company, Inc.

Retrieved from: http://www.hhpublishing.com/_assessments/lassi/lassi_users_manual.pdf 